testing would "undermine" efforts by the international community to achieve disarmament. "The question of the threshold is a much bigger issue than the French decision to carry out eight more tests", says Patricia Lewis, head of VERTIC.

Conventional nuclear weapons could not be tested fully within the proposed threshold of 500 tonnes. But such tests would provide nuclear weapons states with data that would give them added confidence in a new design, says Lewis.

She adds that the thresholds being proposed are in the range that is "crucial for weapons design work". In a recent report, the NRDC also argued that such thresholds would allow study of thermonuclear fusion, and the yield of new "boosted" fission designs.

In a curious twist in the dispute over the scope of the CTBT, a senior military official said last week that if France is allowed to carry out its planned tests in the South Pacific, it would back down on its demand that low-yield tests be exempt from the CTBT.

"If France goes ahead with the tests it will not demand a threshold in the CTBT," he says. "We are willing to drop the threshold as a gesture of self-restraint aimed at helping international cooperation."

His remarks are consistent with comments attributed to Jacques Bouchard, the head of the military applications division of the French Atomic Energy Commission (CEA), in a report by the NRDC and the Federation of American Scientists (FAS), a Washington-based lobby group. Bouchard was quoted as having said last year that "the alternative to France conducting a series of nuclear tests would be to insist on a CTBT that would allow tests of at least 100 tons".

Declan Butler

\title{
Physicists reveal glimpses of Japan's atomic bomb effort
}

Tokyo. As the fiftieth anniversary of the end of the war in the Pacific approaches, details are beginning to emerge of the little-known efforts by Japanese scientists to develop an atomic bomb during the Second World War.

Tatsusaburo Suzuki, an 83-year-old former researcher who was sent by a military institute in 1944 to work on the project at the Institute of Physical and Chemical Research (RIKEN), told a press conference in Tokyo last week that Japan had the necessary expertise to build the bomb but lacked sufficient resources.

"Towards the end of the war, some experts thought it would take us about 100 years to build the bomb," he is reported to have told the Tokyo meeting. "I was of the opinion that if we spent 100 times more in research efforts, we could have developed the bomb in one year."

According to a leading Japanese physicist who was a student at Osaka University during the war, there were three groups in Japan working on what was called the 'uranium bomb'. One group at RIKEN was headed by the institute director, Yoshio Nishina, an eminent nuclear physicist who had studied under Niels Bohr in Denmark. A second group at Osaka University was led by Seishi Kikuchi, another eminent physicist. A third group was at Kyoto University.

Two approaches were pursued, the electromagnetic separation of uranium 235 and separation by a thermal diffusion process. For the second of these, Kikuchi's group at
Osaka built a tall double pipe system extending through several floors of the building. But it was not very successful, and according to one member of the group, it switched to research on a high-powered magnetron before the end of the war.

Very little is known about the research carried out at RIKEN. All records were destroyed after the war, and a spokesman for the institute says "we have no materials". But it is known that the institute was the target of US bombing raids because of its work on nuclear research, and that it suffered severe damage during a raid in April 1945.

But most Western experts conclude that Japan was far behind the United States, Great Britain and Germany in attempting to develop a bomb.

Nevertheless, even after the war RIKEN suffered badly for its war-time efforts. In November 1945, engineers from the US occupation forces dismantled two cyclotrons at the research institute and dumped them in Tokyo Bay. Cyclotrons at Kyoto and Osaka universities suffered similar fates. This was a major setback for Japan's highenergy physics research from which it took decades to recover.

In theory, the cyclotrons could have been used to separate uranium isotopes. But in practice they would have been unable to produce sufficient quantities for a bomb, and the cyclotron destruction was widely condemned by the US high-energy physics community at the time. David Swinbanks

\section{Congress saves Cassini, but targets infrared astronomy mission}

Washington. Only eight days after its threatened demise, the international Cassini mission to Saturn was rescued last week in the US Congress, as the House of Representatives Appropriations committee restored the project's full funding request of $\$ 249$ million for 1996.

The committee also reversed a subcommittee's decision to close three field centres belonging to the National Aeronautics and Space Administration (NASA) (see Nature 376, 203; 1995), and called for an agency restructuring study instead. But the Mission to Planet Earth and the proposed Space Infrared Telescope Facility (SIRTF) both suffered budget cuts as NASA rides a roller-coaster through the congressional appropriations process.

In restoring the Cassini money deleted by a subcommittee, the full committee acknowledged the project's importance and virtually ensured that it will remain on track for a 1997 launch. But the money had to come from somewhere, and the committee therefore took $\$ 339$ million out of a \$1.34-billion request for Mission to Planet Earth, which includes the Earth Observing System (EOS).

It also reduced the budget for the airborne SOFIA infrared astronomy programme by nearly half, to $\$ 28.7$ million. While the Gravity Probe-B relativity experiment received full funding at $\mathbf{\$ 5 1 . 5}$ million, SIRTF was given no money for next year. NASA had asked for $\mathbf{\$ 1 5}$ million to continue studying the project in 1996, with spacecraft development to begin in 1998 and launch planned for 2002 .

The House Science committee, chaired by Robert Walker (Republican, Pennsylvania), which produced a NASA authorization bill last week, also recommended scaling back EOS and deleting SIRTF funds in 1996. According to staff members, the committee's intention is not to kill SIRTF but merely to delay it until funds become available as other expensive missions such as Cassini get closer to their launch dates.

The project is seen as the infrared entry in NASA's suite of 'great observatories'. These include the Hubble Space Telescope, the Compton Gamma Ray Observatory and the Advanced X-Ray Astrophysics Facility (AXAF). Advisory committees from the National Academy of Sciences have consistently given SIRTF high priority among proposed astronomy projects. But its high cost $(\$ 560$ million), its lack of international participation and the fact that it is not yet under way has made it a tempting target for budget-cutters.

According to NASA managers, without the 1996 money the launch would slip by a year, and some of SIRTF's scientific return would be compromised, as it would not be able to conduct as many coordinated observations with other space observatories. A launch in $\mathbf{2 0 0 3}$ would miss most of the opportunity to overlap with the Hubble Space Telescope, as well as any overlap with AXAF.

Tony Reichhardt 